\title{
A Psicologia como reflexão sobre as práticas humanas: da adaptação à errância
}

\author{
Marcia Moraes \\ Universidade Federal Fluminense
}

\begin{abstract}
Resumo
O objetivo desse artigo é apresentar algumas questões que nortearam a Psicologia no século XX. Propomos uma discussão epistemológica acerca da Psicologia e de suas práticas, discutindo os limites do conceito de adaptação à luz da noção de rede, tal como apresentada nos trabalhos de Bruno Latour.
\end{abstract}

Palavras-chave: psicologia; adaptação; redes

\begin{abstract}
Psychology between adaptation and mistake. The goal of this paper is to present ideas that led psychology on the XX century. We submit an epistemological debate about psychology and its actions, discussing the limits of the adaptation concept under the focus of network notion, as presented by Bruno Latour studies.

Key words: psychology; adaptation; networks
\end{abstract}

$\mathrm{O}$ estudo da história da psicologia nos mostra a insistência e a recorrência de um problema: a questão do erro - seja o erro dos sentidos no exercício do conhecimento, na psicologia do século XIX, seja o erro das práticas humanas, na psicologia do século XX. A insistência desse problema leva-nos a uma interrogação: por que o problema do erro é tão fundamental para a psicologia? De que modo a psicologia lida com o problema do erro? São questões que devem ser discutidas num contexto epistemológico. A esse respeito consideramos pertinente acompanhar a questão do erro, tendo como fio condutor dois modos de lidar com esta questão. O primeiro consiste em considerar o erro como o avesso do acerto, como algo a ser superado e corrigido numa norma. Tal é o estilo que marca a psicologia orientada pelo projeto de definir-se como ciência experimental, natural. Já o segundo consiste em considerar o erro como positividade, isto é, como solo de invenção de práticas sociais, como solo de invenção do homem. Esse segundo ponto de vista pode ser elaborado a partir dos trabalhos de Canguilhem a respeito das distinções entre o normal e o patológico ${ }^{1}$, bem como a partir das recentes contribuições de Bruno Latour que, se aliando a tópicos presentes na filosofia de G. Deleuze e F. Guattari, analisa as práticas científicas, não a partir do seu método, mas sim a partir das conexões sempre heterogêneas que sustentam a produção do fato. Trata-se de uma análise das ciências que as considera como práticas produtoras de fatos, como práticas de conexão, de aliança entre humanos e não-humanos. O interessante no estudo dos trabalhos de Bruno Latour é o lugar concedido ao erro no domínio das práticas científicas. Nesse caso, o erro é considerado como algo positivo, como solo de invenção de normas temporárias, instáveis e locais.

\section{Impasses no projeto da psicologia como ciência}

Em um texto em que analisa a psicologia de 1850 à 1950, Foucault (1990) levanta questões importantes quanto ao tema da cientificidade da psicologia e seu estatuto polêmico. Segundo Foucault, a psicologia do século XIX herdou do Iluminismo a preocupação de encontrar no homem as mesmas leis que regem os fenômenos naturais. A psicologia então se ergueu como um esforço metodológico tomado de empréstimo das ciências da natureza e se assentou sobre dois postulados principais: em primeiro lugar, que a verdade do homem se esgotava em seu ser natural e, em segundo lugar, que o caminho de todo conhecimento científico devia passar pela determinação de relações quantitativas, pela construção de hipóteses e pela verificação experimental. Foucault salienta que até a metade do século XX a história da psicologia é a história paradoxal das contradições entre o projeto de reconhecer no homem as mesmas leis que regem a natureza e os postulados que norteiam a construção da psicologia como ciência objetiva. Em outras palavras, com o intuito de mostrar que o homem era uma extensão da natureza, a psicologia ergueu-se a partir dos postulados de rigor, objetividade, neutralidade. No entanto, sua história foi marcada por sucessivos impasses e dificuldades na execução desse projeto 
e daí decorre o caráter paradoxal e contraditório que atravessa a história da psicologia. A precisão matemática e o rigor experimental encontravam limites de aplicação no caso do saber psicológico. No século XIX, a psicologia se constituiu com o objetivo de investigar as condições subjetivas responsáveis pelos equívocos no exercício do conhecimento. Para isso, a psicologia se fez uma física dos sentidos externos, apesar de se manter sempre no limite entre uma ciência objetiva acerca do sujeito cognoscente e uma metafísica das condições do conhecimento. Dito de outro modo, no século XIX, a psicologia se definia mais como um campo de tensão entre a física e a filosofia do que como uma ciência experimental do sujeito cognoscente. Os debates entre Wundt e seus críticos, como Ebbinghaus, são a esse respeito exemplares. Enquanto o primeiro era acusado de confundir psicologia com metafísica, o segundo afirmava a viabilidade de uma ciência experimental dos processos mnêmicos, desde que estes fossem definidos por meio do conceito de associação. Ao comentar esse estatuto tenso, paradoxal e contraditório da psicologia, Foucault destaca que

... o projeto de rigorosa exatidão que conduziu a psicologia passo a passo a abandonar seus postulados tornou-se vazio de sentido quando esses postulados desapareceram: a idéia de uma precisão objetiva e quase matemática no domínio das ciências humanas não é mais saber se o homem ele mesmo é da ordem da natureza. É então a uma renovação total que a psicologia é constrangida no curso de sua história; descobrindo um novo estatuto do homem, ela se impôs como ciência, um novo estilo. (Foucault, 1990, p. 160)

A questão que importa ser ressaltada, conforme salienta Foucault na citação acima, não é retomar o tema da inserção ou não do homem no domínio das ciências naturais, mas sim de tomar como fio condutor para a invenção de um novo estilo de ciência os paradoxos enfrentados pela psicologia em seu projeto de se estabelecer como ciência experimental do sujeito cognoscente. Isso significa dizer que os embates e os problemas enfrentados pela psicologia para fazer do sujeito do conhecimento uma extensão da ordem natural são antes a condição para a invenção de um certo estilo de ciência, que não se confunde com o modelo das ciências naturais no século XIX. Trata-se, conforme salienta Foucault, de uma dupla tarefa incompreendida pelos psicólogos em todo o seu alcance e que eles têm tentado por vezes fazer da exigência de novos projetos uma expansão dos princípios do método: as psicologias da conduta são a esse respeito emblemáticas uma vez que tentaram analisar a conduta, embora utilizassem para isso os métodos da ciência da natureza; outros não compreenderam que a renovação dos métodos implicava o levantamento de novos temas de análise: foi o que aconteceu com as psicologias descritivas que permaneceram vinculadas a velhos conceitos. Nesse sentido, Foucault registra que uma renovação radical da psicologia como ciência do homem é uma tarefa incompleta a cumprir e que está na ordem do dia.
A psicologia e as práticas humanas ou a questão da adaptação

Foucault (1990) afirma que nos últimos 100 anos a psicologia estabeleceu relações novas com a prática: educação, medicina mental, organização dos grupos. Essa prática tem se apresentado como o solo de fundação racional e científico da psicologia. Além disso, a psicologia se propõe questões oriundas dessas práticas: o problema do êxito ou do fracasso escolar, problema da adaptação do homem às suas condições de trabalho, as relações entre o doente e a sociedade. É interessante notar que, por esse laço constante com a prática, pela reciprocidade de suas trocas, a psicologia no século XX se tornou semelhante a todas as ciências da natureza. Mas é preciso fazer uma ressalva, conforme adverte Foucault (1990). Enquanto as ciências naturais respondem apenas pelos problemas colocados pelas dificuldades da prática, seus fracassos temporários, as limitações provisórias de sua experiência, a psicologia, ao contrário, nasce no ponto em que a prática do homem encontra sua própria contradição; no ponto em que essa prática falha, erra. A psicologia do desenvolvimento nasceu como uma reflexão sobre as dificuldades do desenvolvimento; a psicologia da conduta, como uma análise dos desajustes, aquela da memória, da consciência, do sentimento, do pensamento apareceu de início como uma psicologia do esquecimento, do inconsciente, das perturbações afetivas e dos problemas do pensamento. Por isso, Foucault (1990) conclui que “a psicologia contemporânea é uma análise do anormal, do patológico, do conflitual, uma reflexão das contradições do homem com ele mesmo”. E, ele prossegue, "se ela se transformou numa psicologia do normal, do adaptativo, do ordenado, é de uma maneira secundária, como por um esforço para dominar essas contradições" (Foucault, 1990, pp.160-161).

No início do século XX a questão do desajuste do comportamento humano tornou-se pregnante no campo da psicologia. Para adaptar o indivíduo às novas condições de vida que emergiam nos EUA por essa época era de fundamental importância que fossem conhecidas as leis reguladoras do comportamento humano. Conhecendo tais leis, seria possível intervir sobre a prática humana de modo a promover indivíduos ajustados ao seu meio social. Com uma ferramenta desse porte seria possível ajustar o comportamento de um trabalhador de modo a obter dele o máximo de rendimento possível com o mínimo de custo para uma empresa. Do mesmo modo, seria possível ajustar o comportamento de uma criança à situação escolar e, em última instância, adaptar o comportamento do indivíduo à sociedade.

A emergência da psicologia do comportamento foi marcada por estas exigências técnicas e econômicas. Foi uma sociedade capitalista e industrializada que se perguntou não acerca do conhecimento humano - questão por demais especulativa - mas sim, acerca da prática humana. O fundamento filosófico de uma indagação deste tipo é o 
instrumentalismo que supõe que "a natureza do homem é de ser ferramenta, sua vocação é ser colocado no seu lugar, na sua tarefa” (Canguilhem, 1972, p. 120).

O paradigma científico dessa psicologia remete à biologia de Darwin e ao conceito de adaptação como eixo da relação entre o organismo e o meio. Nesta perspectiva, pode-se afirmar que o meio apresenta problemas que o organismo responde adaptando-se ou morrendo. O critério para avaliar um comportamento ajustado é dado pela sobrevivência. Assim, o organismo biológico modifica-se progressivamente segundo as exigências de seu meio.

O conceito de adaptação da biologia foi tomado pela psicologia como chave para explicar a prática humana. Em psicologia a adaptação refere-se não tanto a uma relação entre o organismo e o meio biológicos, mas, principalmente, a uma relação entre indivíduo e meio social. Com este esqueleto conceitual a psicologia pretendia dar conta das questões empíricas que a industrializada sociedade estadunidense lhe apresentava. Constituiu-se então uma psicologia do comportamento humano como uma ciência que descrevia as leis do comportamento e que, por esta via, servia como um instrumento para promover a adaptação do indivíduo ao meio social. Conhecendo as leis de produção de um comportamento seria possível alterá-lo. Deste modo, a psicologia definiu-se como uma técnica e não mais como pura especulação filosófica. Uma psicologia made in USA e que, como tal, se caracterizou por seu utilitarismo. Colocar o homem certo no lugar certo, eis a tarefa do psicólogo.

Neste ponto nos deparamos com um problema essencial. Se na biologia o parâmetro para definir a adaptação é a sobrevivência, o mesmo não ocorre na psicologia. Aqui, a referência para um comportamento ser classificado como ajustado não pode ser natural, biológica, uma vez que está em cena um indivíduo num meio social e não um organismo biológico num meio natural. Como então definir um comportamento adaptado num meio social? Qual será o critério a ser utilizado para determinar o que é, ou não, adaptado? O critério neste caso só pode ser arbitrário. Isto significa dizer que, em relação ao meio social, o parâmetro do comportamento ajustado é dado por quem detém o poder e o controle sobre a prática humana. Desta maneira, o psicólogo passa a ser ele próprio um instrumento a serviço daquele que lhe fornece o termômetro para avaliar o grau de desajuste do comportamento humano. Em outras palavras, o psicólogo passa a ser

um prático profissional cuja "ciência” é totalmente inspirada na pesquisa das "leis” da adaptação a um meio sócio-técnico e não a um meio natural - o que confere sempre a estas operações de "medida” uma significação de apreciação e um alcance de perícia. (Canguilhem, 1972, p.121)

Nessas considerações sobre a questão da adaptação na psicologia, interessa-nos delimitar o estatuto polêmico e paradoxal desse tema. Dito de outro modo, o que nos parece interessante no tema da adaptação é que ele aponta para o caráter sempre paradoxal das práticas humanas. Delimitar o estudo da adaptação em torno da pesquisa das leis gerais que regulam esse processo não nos parece ser o ponto mais importante. Para nós, o mais importante é que a adaptação do homem ao meio social é marcada pela contradição, pelos desajustes, pelas errâncias.

\section{Dos desajustes às errâncias}

Nesse ponto é importante retomarmos a questão que levantamos mais acima: por que o problema do erro - ou do desvio, do desajuste - é tão fundamental para a psicologia? Conforme vimos, a psicologia, como aliada a uma "ortopedia" das práticas humanas, faz do desajustamento o reverso do comportamento ajustado e, como tal, portanto, um fato a ser corrigido, contornado ou justificado por uma lei geral. No entanto, o problema do erro indica uma outra direção: no enfoque deleuziano, o erro não é um fato que deve ser corrigido e superado. Ele é um acontecimento de direito. Isso significa tomar o erro num sentido radical de errância, deriva, devir constitutivo do pensamento. Não se trata de tomar o erro como o par oposto do verdadeiro, mas de considerá-lo como errância, como um modo peculiar de distribuição do ser.

Deleuze (1988) indica que, do ponto de vista do ser, há dois tipos de distribuição e hierarquia: uma sedentária, na qual os seres são medidos "segundo seus limites e segundo seu grau de proximidade ou distanciamento em relação a um princípio”(p. 77). Segundo Deleuze (1988), “esse tipo de distribuição procede por determinações fixas e proporcionais, assimiláveis a 'propriedades' ou territórios limitados na representação”(p. 76). Nesse caso, o erro é medido por sua distância em relação ao verdadeiro.

Além da distribuição sedentária, há uma outra que Deleuze (1988) chama de nomádica, "por ser sem cerca nem medida" (p. 77). Nesse caso, as coisas e os seres são considerados do ponto de vista de sua potência e, vale notar, não se trata de graus de potência tomados como referências absolutas, mas sim de "saber se um ser salta eventualmente, isto é, ultrapassa seus limites, indo até o extremo daquilo que pode, seja qual for o grau” (p.78). Ultrapassar os limites não tem aqui o sentido de um término; o limite deixa de designar "o que mantém a coisa sob uma lei” para indicar um ponto de partida, "aquilo a partir do que a coisa se desenvolve e desenvolve toda sua potência” (p.78). As distribuições nômades introduzem perturbações, desvios, errâncias nas distribuições sedentárias e, nesse caso, erro é sinônimo de errância.

Tratar das distribuições nômades e sedentárias não implica a afirmação de um dualismo, isto é, não há uma oposição recíproca entre os dois tipos de distribuição; ao contrário, ocorre que os seres se distribuem numa escala de variável desmesura. As distribuições nomádicas fazem derivar as distribuições de tipo sedentário, é o caso de uma deriva ontológica. Assim, parece-nos possível dizer que, se por um lado, o erro é tomado como um fato a ser corrigido, por outro lado, do ponto de vista de uma ontologia da diferença, ele é sempre afetado por uma errância, por um nomos ou por uma distribuição nomádica. A questão ainda em aberto é justamente saber se a insistência do tema do erro no campo da psicologia, bem como os seus impasses para se propor como justificativa para esse erro, não decorre de uma insistência desse campo de distribuições nômades, campo problemático. Dito de outro modo, parece-nos que a 
possibilidade de erro pode referir-se tanto a um equívoco do sujeito ou à falha de uma prática quanto a essa desmesura do ser ou, o que dá no mesmo, aos devires de um vivido ontológico sub-representativo. A questão pertinente para a psicologia nos dias atuais é saber em que medida os seus impasses frente aos problemas do erro, dos desajustes, das falhas na cognição e nos diversos domínios da prática são as condições de formulação de um novo estilo de ciência, um estilo de ciência que comporte em seu bojo a deriva, a errância não como algo a ser corrigido e superado, mas como uma positividade, solo de fundação de um processo de diferenciação imanente.

\section{Um estilo de ciência para a psicologia?}

$\mathrm{Na}$ atualidade alguns autores operam um deslocamento no que diz respeito às discussões epistemológicas acerca das ciências e de suas práticas. Entre esses autores, podemos citar Bruno Latour, que em sua obra apresenta os limites das definições racionalistas da ciência. Na perspectiva desse autor, a ciência se define como uma prática de mobilização de aliados heterogêneos, aliados humanos e não-humanos. Nesse ponto, perguntamos se a teoria ator-rede, proposta por Latour (1994), Callon (1986) e outros autores, pode servir de aliada para o debate em torno da cientificidade da psicologia e da insistência do tema do erro em seu campo de estudos.

\section{Sobre as redes}

$\mathrm{Na}$ teoria ator-rede, a noção de rede refere-se a fluxos, circulações, alianças, movimentos em vez de remeter a uma entidade fixa. Uma rede não se reduz a um ator sozinho. Ela é formada por séries heterogêneas de elementos, humanos e não-humanos conectados. Por um lado, a rede de atores deve ser diferenciada dos tradicionais atores da sociologia, uma categoria que exclui qualquer componente não-humano. Por outro lado, a rede também não pode ser confundida com um tipo de vínculo que liga de modo previsível elementos estáveis e perfeitamente definidos, porque as entidades da quais ela é composta, sejam elas naturais, sejam sociais, podem a qualquer momento redefinir sua identidade e suas mútuas relações, trazendo novos elementos para a rede. Assim, uma rede de atores é simultaneamente um ator, cuja atividade consiste em fazer alianças com novos elementos, e uma rede capaz de redefinir e transformar seus componentes.

A noção de rede de atores diz respeito a um plano de conexões heterogêneas a partir do qual emergem tanto as ciências quanto as crenças, as religiões, etc. Podemos dizer que ela se caracteriza por estabelecer um campo de tensões heterogêneas no qual a síntese não é um resultado necessário. Latour (1994) afirma a rede como uma ontologia de geometria variável, isto é, como um plano ontológico marcado por múltiplas entradas. Nesse sentido, a análise das ciências é apresentada sem partir de pólos privilegiados, como o sujeito e o objeto, o acerto e o erro. O princípio de simetria generalizada proposto por Latour é uma conseqüência dessa ontologia de múltiplas entradas e conexões. Trata-se de analisar simetricamente não apenas o erro e o acerto, mas antes, todo e qualquer efeito das negociações em rede, dentre eles, a natureza e a sociedade. Levando mais longe as análises sociais da ciência e de suas práticas, Latour (1994) propõe o princípio de simetria generalizado, fazendo-o valer tanto para a natureza quanto para a sociedade. Para estabelecer uma simetria generalizada, é preciso uma guinada a mais nos estudos sobre as ciências, de modo que a sociedade assim como a natureza sejam simetricamente estudadas. Natureza e sociedade são efeitos negociados em rede, nem uma nem outra podem funcionar como fundamentos preestabelecidos para os estudos sobre ciências. O princípio de simetria não tem como finalidade apenas estabelecer uma condição de igualdade entre natureza e sociedade. Ele tem por finalidade "gravar as diferenças, ou seja, no fim das contas, as assimetrias, e o [objetivo] de compreender os meios práticos que permitem aos coletivos dominarem outros coletivos” (Latour, 1994, p.105).

As redes não são, portanto, amorfas. Ao contrário, elas são altamente diferenciadas. Eliminar a oposição binária entre sujeito e objeto não implica a afirmação de um solo homogêneo e indiferenciado. Está em foco a afirmação de uma diferença ontológica. A rede é, nesse sentido, uma afirmação dessa diferença. Ela consolida a potência do empírico como solo de invenção da razão, da verdade, da sociedade, da natureza.

Uma ciência definida como rede de atores não se caracteriza por sua racionalidade, sua objetividade ou pela veracidade dos fatos por ela engendrados. Todas essas noções são redimensionadas pela noção de rede e devem ser entendidas como efeitos, resultados alcançados a partir das tensões próprias à rede de atores. Definir a ciência como rede de atores significa defini-la por sua não-modernidade, por suas hibridações, enquanto considerar as ciências a partir de noções tais como objetividade, neutralidade, etc., implica considerá-las à luz do ideal de purificação, princípio característico do pensamento crítico ou moderno. Podemos dizer que, analisando as ciências simetricamente, isto é, sem privilegiar os acertos, nem nenhum outro a priori, Latour coloca em cena os múltiplos atores que definem a prática científica: os cientistas, os dispositivos técnicos, o dinheiro, as revistas de divulgação científica... São atores que, de um modo ou de outro, estão presentes nas práticas científicas. Nesse sentido, as ciências são analisadas não do ponto de vista dos seus resultados, mas do ponto de vista do processo de construção de um fato. Isso significa colocar o acento na investigação da ciência enquanto prática, na análise do trabalho dos cientistas na bancada dos laboratórios. A análise do processo de construção do conhecimento coloca em cena a rede como o solo no qual o conhecimento é produzido.

A noção de rede tal como é apresentada por Bruno Latour situa a ciência numa charneira entre a filosofia da diferença de Deleuze \& Guattari (1992) e a psicologia. Considerada como um conjunto de conexões performativas entre elementos heterogêneos, a ciência se apresenta como migração de uma distribuição nômade. Em outras palavras, o enfoque proposto por Bruno Latour nos permite pensar um estilo de prática científica que comporte em seu âmbito uma errância, uma deriva típica de uma distribuição nômade. Ao comentar as relações 
entre filosofia e ciência, Deleuze \& Guattari afirmam que “erigir um conceito [filosófico] não é a mesma coisa que traçar uma função [científica], embora haja movimento dos dois lados, embora haja transformações e criações num caso como no outro: os dois tipos de multiplicidade se entrecruzam" (Deleuze \& Guattari, 1992, p. 205). A teoria ator-rede afirmada por Latour, Law, Callon, entre outros, confere visibilidade ao entrecruzamento entre os dois tipos de multiplicidade, filosófica e científica. Por esse motivo, pensamos que a noção de rede é de crucial importância para a invenção de um novo estilo de ciência para a psicologia, um estilo que considera o erro, no sentido de uma distribuição nomádica. Uma ciência definida, portanto, como um engajamento prático-teórico estabelecido por meio de conexões de interesse e que, por este motivo, não pode ser encerrada em nenhum a priori situado para além dos riscos de sua prática.

\section{Redes e psicologia}

A noção de rede permite reativar o campo problemático constitutivo da psicologia: seus impasses para se constituir como uma ciência que, pela proposição de leis gerais, funcione como justificativa para o problema do erro, seja na cognição, seja no domínio da prática. Reativar esse campo problemático significa arrastar as questões relativas ao erro na direção daquilo que se apresenta como o seu solo de fundação: as distribuições nômades, distribuições de errância. Quais os efeitos desse movimento? Aqui vale parafrasear Orlandi (1996) que, ao comentar as diferenciações introduzidas pelo problemático no pensamento, utiliza uma analogia das relações entre o vento e as nuvens e diz: “os ventos estão para as nuvens-com-suas-figuras assim como o problemático está para o pensamento-com-suas-disciplinas” (p.28). Parafraseando o autor, podemos dizer que os ventos estão para as nuvens-com-suas-figuras assim como a rede está para a ciência-com-suas-ortodoxias. A ontologia em rede arrasta as formas estáveis da ciência, tais como rigor, objetividade, verdade, na direção de um processo imanente de diferenciação. Considerar a psicologia como uma ciência em rede, uma ciência em ação, significa pensar um novo estilo de ciência para a psicologia e, conseqüentemente, significa deixar derivar as suas formas estabelecidas: as discussões em torno de sua cientificidade, as controvérsias em relação aos seus métodos e objetos, as questões relativas à sua unidade ou dispersão, as polêmicas quanto à sua autonomia frente aos demais saberes. Uma deriva que certamente também abarca os seus campos de estudo: a cognição ou qualquer domínio da prática.

\section{Referências}

Callon, M. (1986). Society in the making: the study of technology as a tool for sociological analysis. In W. Bijker, T. P. Hughes, \& T. Pinch (Orgs.), The social construction of technological systems. New directions in the sociology and history of technology (pp. 83-103). Cambridge, Massachusetts: The MIT Press.

Canguilhem, G. (1972). O que é a Psicologia? Revista Tempo Brasileiro, 30/ $31,104-123$.

Deleuze, G. (1988). Diferença e repetição. Rio de Janeiro: Graal.

Deleuze, G., \& Guattari, F. (1992). O que é a Filosofia? Rio de Janeiro: Ed. 34.

Foucault, M. (1990). La Psychologie de 1850 à 1950. Revue Internationale de Philosophie, 173(2), 159-176.

Latour, B. (1994). Jamais fomos modernos. Rio de Janeiro: Ed. 34.

Moraes, M. (2000). O conhecimento científico: da epistemologia às redes sócio-técnicas. Arquivos Brasileiros de Psicologia, 3(52), 76-88.

Orlandi, L. B. (1994). Nuvens. Idéias (Campinas), 1, 41-79.

Orlandi, L. B. (1996). Revendo Nuvens. Manuscrito não-publicado. ${ }^{2}$

\section{Notas}

1. A análise do problema do erro proposta por Canguilhem no seu livro O normal e o patológico é bastante interessante para esse debate. Em outro artigo analisamos as conseqüências do trabalho de Canguilhem para a epistemologia da psicologia (ver Moraes, 2000).

2. Esse trabalho é reformulação de artigo anterior (ver Orlandi, 1994).

Marcia Moraes, Mestre em Psicologia Cognitiva pela Universidade Federal do Rio de Janeiro, Doutora em Psicologia Clínica pela Pontifícia Universidade Católica de São Paulo, é Professora Adjunta no Departamento de Psicologia da Universidade Federal Fluminense.

Endereço para correspondência: Rua Desembargador Cesínio Paiva, 15 - São Francisco; Niterói, RJ; CEP 24.360-530. Tel.: (21) 2610-0827. Celular: (21) 9631-9409.E-mail: mmoraes@nitnet.com.br 